suspending wire-fibre. The drop to zero is simultaneous with each flash of lightning. So certain is this relation that we can time the lightning flashes without seeing them. After the flash the needle begins to again move in one direction, repeating its previous behaviour, so that our electrometer measurements seem to prove that every flash of lightning relieves the state of stress of the air, which we may compare with the glass in a Leyden jar, the cloud and ground being the respective coatings.

We may also get at the same result by noticing the effects of the electrification of the dust, smoke, water, and other matter in the air. Whenever our "collector" was "grounded," the fine stream of water issuing from it preserved a certain even rounded form, breaking into drops some four inches away from the place of exit. Removing the "ground" connection, and the stream being now under the influence of the thunder-clouds, the steadily increasing electrification shows itself in the stream's twisting and splitting into innumerable threads and spray; but with each flash of lightning the distortion instantly ceases, and the stream has its normal character, only to be again distorted.

For the benefit of those wishing to photograph lightning suggest this as a cheap and easy mode of getting warning when to expose. A small tin case with a nozzle giving a fine thread of water or any form of the "burning match" device, well insulated from the ground, and at some elevation, will indicate by changes in the character of the stream or smoke, the approximate degree of the electrification of the air.

New York, U.S.A., June 20.

Alexander McAdie.

\section{Upper Wind Currents over the Equator in the Atlantic Ocean.}

REFERRING to the remarks of the Hon. RaIph Abercromby on the above in Nature of May 30 (p. IOI), I would ask for the longitude and latitude for the two crossings of the doldrums, to enable one properly to follow, and eventually work out, the facts. For if our famous meteorologist, on the outer journey, passed within one hundred miles of the West Coast of Africa, the great chain of desert lands, extending many hundreds of miles through Asia to the Sahara in the main weather thoroughfare, would, by its influence, very much contract the width of the calm belt, and otherwise draw the doldrum much north of the line to what would be found more to the westward, where, as it neared the American coast, the breadth of the doldrum belt would very greatly increase; so that, unless the doldrum was crossed at the same longitude, the varying atmospheric conditions should not be put down solely to the sun, or difference of December and May seasons.

Perhaps it is from want of the longitude that I am unable to understand "how low clouds from the south-east drove over north-east trades up to $15^{\circ}$ north." All else is exceedingly satisfactory with the law of winds, on the supposition that the return crossing of the doldrum belt took place some hundreds of miles further west, and about half that distance farther. south, than on the out journey.

If I may be allowed to digress a little, I would refer to the splendid travels by your correspondent, as published last Christ. mas under the title of "Seas and Skies in many Latitudes," which in some respects, I think, may be compared with the celebrated Challenger Expedition. But, singularly enough, while I am able to follow and accept all the author's research and information, I find myself diametrically opposed to his conclusions. Thus, to quote from p. 428 , we have: "Hence we see the proof of the assertion that the trades and monsoons do not meet and force one another to rise, and flow back poleward, but that the two winds coalesce and form one great eastern current over the doldrum." To my mental capacity all the proof is the other way about. If the trades of both hemispheres do not ascend over the calm belt, what other escape or vent is there for them? I am aware that the Meteorological Section of the Krakatão Committee of the Royal Society also favour the idea of a great easterly current ever going west at a certain altitude over the doldrums, but so far as I can find out they do not tell us whence it cometh nor whither or how it goeth. In its circuit going west, we naturally look for its return from the east, and with the constant arrival of fresh winds via the trades of both hemispheres, it must accumulate if it does not flow back poleward quite as fast as it arrives, for we cannot entertain annihilation of atmosphere any more than of matter. If some other way of escape could be found, we should still have to face the question, Whence comes the supply to the " trades if not from the poles, and whence our prevailing south-westerly winds if not from over the doldrums "?

E. FOULGER.

Liverpool, June I8.

P.S.-I do not call in question "the great easterly current over the doldrum," but rather consider its discovery as extremely interesting, it being just what a small school of meteorologists would expect; and it now appears to be left for them to supply a theory for the cause of the direction and also of the motive power of such an atmospheric passage, and possibly for that of the Krakatão dust.

E. F.

\section{Patches of Prismatic Light.}

I AM curious to know if any of your readers observed the following phenomenon in the sky, and could give any information as to its nature.

When driving with two friends on Saturday evening, June 22 between 6.30 and 7 p.m., in the neighbourhood of Glatton, near Peterborough, we observed on either side of the sun (the sky being almost cloudless) two patches of prismatic light; they appeared to be of nearly the same size as the apparent disk of the sun, and distant from it a hand's span measured from little finger to thumb at arm's length. At the time there were a few light clouds about, but the prismatic patches were not projected on them, as the clouds passed occasionally in front of them, the patches meanwhile shining through the thinnest parts, and reappearing when the clouds had passed, clearly standing out against the sky. There was no appearance of a continuous arch, as in a rainbow, and, unlike a rainbow, the patches were on the same side of the sky as the sun. I may add that the phenomenon was seen by all three of us, and for half an hour after we first noticed it.

Glatton Hall, Peterborongh, June 28.

C. S. SCOTT.

\section{A Chimpanzee's Humour.}

IN a recent lecture $\mathrm{Mr}$. Romanes is reported as having strongly denied the existence of even a trace of any feeling of the ludicrous in the renowned chimpanzee "Sally." It may be worth while to record a small fact observed by me lately, tencing, I think, to favour an opposite view.

Being alone with a friend in Sally's house, we tried to get her to obey the commands usually given by the keeper. The animal came to the bars of the cage to look at us, and, adopting the keeper's usual formula, I said, "Give me two straws, Sally." At first she appeared to take no notice, although she had been eyeing us rather eagerly before. I repeated the request with no further result ; but on a second or third repetition she suddenly took up a large bundle of straw from the floor and thrust it through the bars at us, and then sat down with her back to us. Our request was perhaps unreasonable, seeing that we had no choice morsels of banana with which to reward her. She did not, however, seem ill-temperes at our presumption, and the next instant was as lively as ever. It seems to me that her action on this occasion certainly came very near to an expression of humour. Rather sarcastic humour perhaps it was, but she certainly appeared to take pleasure in the spectacle of something incongruous, and this surely lies at the base of all sense of the ludicrous.

July $\mathrm{r}$.

Harold Picton.

\section{PROF. HUXLEY AND M. PASTEUR ON HYDROPHOBIA.}

$\mathrm{N}$ Monday afternoon the meeting called by the Lord Mayor to hear statements from men of science with regard to the recent increase of rabies in this country, and the efficiency of the treatment discovered by M. Pasteur for the prevention of hydrophobia, was held at the Mansion House. Much excellent work was done. Several letters were read from those who were unable to attend. Among these letters was the following from Prof. Huxley :-

"Monte Generaso, Switzerland, June 25, 1889.

"MY LORI MAYOR,-I greatly regret my inability to be present at the meeting which is to be held, under your 
Lordship's auspices, in reference to M. Pasteur and his Institute. The unremitting labours of that eminent Frenchman during the last half-century have yielded rich harvests of new truths, and are models of exact and refined research. As such they deserve, and have received, all the honours which those who are the best judges of their purely scientific merits are able to bestow. But it so happens that these subtle and patient searchings out of the ways of the infinitely little--of that swarming life where the creature that measures one-thousandth part of an inch is a giant--have also yielded results of supreme practical importance. The path of M. Pasteur's investigations is strewed with gifts of vast monetary value to the silk trader, the brewer, and the wine merchant. And this being so, it might well be a proper and a graceful act on the part of the refresentatives of trade and commerce in its greatest centre to make some public recognition of M. Pasteur's services, even if there were nothing further to be said about them. But there is much more to be said. M. Pasteur's direct and indirect contributions to our knowledge of the causes of diseased states, and of the means of preventing their occurrence, are not measurable by money values, but by those of healthy life and diminished suffering to men. Medicine, surgery, and hygiene have all been powerfully affected by M. Pasteur's work, which has culminated in his method of treating hydrophobia. I cannot conceive that any competentlyinstructed person can consider M. Pasteur's labours in this direction without arriving at the conclusion that, if any man has earned the praise and honour of his fellows, he has. I find it no less difficult to imagine that our wealthy country should be other than ashamed to continue to allow its citizens to profit by the treatment freely given at the Institute without contributing to its support. Opposition to the proposals which your Lordship sanctions would be equally inconceivable if it arose out of nothing but the facts of the case thus presented. But the opposition which, as I see from the English papers, is threatened has really for the most part nothing on earth to do either with M. Pasteur's merits or with the efficacy of his method of treating hydrophobia. It proceeds partly from the fanatics of laissez faire, who think it better to rot and die than to be kept whole and lively by State interference, partly from the blind opponents of properly-conducted physiological experimentation, who prefer that men should suffer rather than rabbits or dogs, and partly from those who for other but not less powerful motives hate everything which contributes to prove the value of strictly scientific methods of inquiry in all those questions which affect the welfare of society. I sincerely trust that the good sense of the meeting over which your Lordship will preside will preserve it from being influenced by these unworthy antagonisms, and that the just and benevolent enterprise you have undertaken may have a happy issue.

"I am, my Lord Mayor, your obedient servant, "Thomas H. Huxley.

" The Right Hon. the Lord Mayor, Mansion House, E.C."

The following letter from M. Pasteur, dated Paris, the 27th ult., was read by Sir H. Roscoe:-

"Dear Colleague and Friend,-I am obliged by your sending me a copy of the letter of invitation issued by the Lord Mayor for the meeting on July I. Its perusal has given me great pleasure. The questions relating to the prophylactic treatment for hydrophobia in persons who have been bitten and the steps which ought to be taken to stamp out the disease are discussed in a manner both exact and judicious. Seeing that hydrophobia has existed in England for a long time, and that medical science has failed to ward off the occurrence even of the premonitory symptoms, it is clear that the prophylactic method of treating this malady which $I$ have dis- covered ought to be adopted in the case of every person bitten by a rabid animal. The treatment required by this method is painless during the whole of its course and not disagreeable. In the early days of the application of this method contradictions such as invariably take place with every new discovery were found to occur, and especially for the reason that it is not every bite by a rabid animal which gives rise to a fatal outburst of hydrophobia. Hence prejudiced people may pretend that all the successful cases of treatment were cases in which the natural contagion of the disease had not taken effect. This specious reasoning has gradually lost its force with the continually increasing number of persons treated. To-day, and speaking solely for the one anti-rabic laboratory of Paris, this total number exceeds 7000 ; or exactly, up to the 3 Ist of May, 1889 , 6950. Of these the total number of deaths was only seventy-one. It is only by palpable and wilful misrepresentation that a number differing from the above, and differing by more than double, has been published by those who are systematic enemies of the method In short, the general mortality applicable to the whole of the operations is I per cent., and if we subtract from the total number of deaths those of persons in whom the symptoms of hydrophobia appeared a few days after the treatment-that is to say, cases in which hydrophobia had burst out (often owing to delay in arrival) before the curative process was completed-the general mortality is reduced to 0.68 per cent. But let us for the present only consider the facts relating to the English subjects whom we have treated in Paris. Up to May $3 \mathbf{I}$, 1889 , their total number was 214 . Of these there have been five unsuccessful cases after completion of the treatment, and two more during treatment, or a total mortality of 3.2 per cent., or more properly 2.3 per cent. But the method of treatment has been continually undergoing improvement, so that in 1888 and 1889 , on a total of sixtyfour English persons bitten by mad dogs and treated in Paris, not a single case has succumbed, although amongst these sixty-four there were ten individuals bitten on the head and fifty-four bitten on the limbs, often to a very serious extent. I have already said that the Lord Mayor in his invitation has treated the subject in a judicious manner, from the double point of view of prophylaxis after the bite and of the extinction of the disease by administrative measures. It is also my own profound conviction that a rigorous observance of simple police regulations would altogether stamp out hydrophobia in a country like the British Isles. Why am I so confident of this? Because, in spite of an old-fashioned and widespread prejudice, to which even science has sometimes given a mistaken countenance, rabies is never spontaneous. It is caused, without a single exception, by the bite of an animal affected with the malady. It is needless to say that in the beginning there must have been a first case of hydrophobia. This is certain ; but to try to solve this problem is to raise uselessly the question of the origin of life itself. It is sufficient for me here, in order to prove the truth of my assertion, to remind you that neither in Norway, nor in Sweden, nor in Australia, does rabies exist; and yet nothing would be easier than to introduce this terrible disease into those countries by importing a few mad dogs. Let England, which has exterminated its wolves, make a vigorous effort, and it will easily succeed in extirpating rabies. If firmly resolved to do so, your country may secure this great benefit in a few years; but, until that has been accomplished, and in the present state of science, it is absolutely necessary that all persons bitten by mad dogs should be compelled to undergo the anti-rabic treatment. Such, it seems, is a summary of the statement of the case by the Lord Mayor. The Pasteur Institute is profoundly touched by the movement in support of the meeting. The interest which His Royal Highness the Prince of Wales has evinced in the pro- 
posed manifestation is of itself enough to secure its success. Allow me, my dear colleague, to express my feelings of affectionate devotion."

\section{AN INDEX TO SCIENCE.}

I HAVE lately received the "Sach Register" of the Berichte der Deutschen Chemischen Gesellschaft, I $868-87$, in three volumes, indexing the twenty years of publication (thirty-six volumes). The work is admirably done, and is of inestimable value to the student of science generally. German scientific men and scientific Societies are far in advance of the English in the art of making the results of scientific research readily accessible. Witness the admirable "Bibliotheca Zoologica," by Engelmann and Carus, and still continued by Taschenberg; the "Sach Registers" to Liebig's Annalen der Chemie, I 832-83, to Poggendorff's (now Wiedemann's) Annalen der Physik und Chemie, I824-87, and to the Journal fiir Praktische Chemie, I833-87; and the "Repertorium Commentationum a Societatibus litterariis editarum," by Reuss, in sixteen quarto volumes, which last valuable production covers the whole ground down to the end of the last century.

The fact is very suggestive with regard to the English neglect of the scientific knowledge, experiment, and discovery locked up in the long series of English scientific journals to be found in our public libraries. The journals have usually, but not always, a short index at the end of each volume, obliging the student to occasionally spend days and weeks in searching through the series for what has been written on a subject he is investigating. The volumes accumulate on the shelves, and the experiments and investigations are repeated again and again.

The Royal Society, with a lively sense of the necessity for a remedy to the existing chaos, some twenty years ago commenced, and continues at intervals the issue of "A Catalogue of Scientific Papers contained in the Transactions of Societies, Journals, and other Periodical Works from the Year I80o." It is an author-list, and does not at all meet the requirements of the case. It necessitates a knowledge, by the inquirer, of the names of all the men who are likely to have written on the subject of inquiry. Life is not long enough for this. Librarians are occasionally of some assistance in the matter, but they often fail. What occurred lately has occurred to me often: I submitted to a chemist of some note the records of experiments published in I820, which would have saved him many months of investigation of the same subject if a reference to the previous work had been accessible by index or by personal knowledge. It is the experience of all men of science that days may be spent in obtaining a reference to what may be read in five minutes, usefully or uselessly.

The Royal Society Catalogue originated from a suggestion of the late Joseph Henry, the Director, for thirty years, of the Smithsonian Institution (Washington) for the Increase and Diffusion of Knowledge, who said ("Smithsonian Miscellaneous Collections," vol. xxi. p. 295):- -

"One of the most important means for facilitating the use of libraries (particularly with reference to science) is well-digested indexes of subjects, not merely referring to volumes of books, but to memoirs, papers, and parts of scientific transactions and systematic works. I know of no richer gift which could be bestowed upon the science of our own day than the provision of these. Everyone who is desirous to enlarge the bounds of human knowledge should, in justice to himself as well as to the public, be acquainted with what has been previously done in the same line."

Henry afterwards communicated with the British Association on the subject (in I 855). The Association appointed a Committee (Mr. Cayley, Mr. Grant, and Prof. Stokes), who reported :-

"The Committee are desirous of expressing their sense of the great importance and increasing need of such a Catalogue. . . . The Catalogue should not be restricted to memoirs in Transactions of Societies, but should comprise, also, memoirs in the Proceedings of Societies, in mathematical and scientific journals, \&c. ... The Catalogue should begin from the year I80o. There should be a Catalogue according to the names of authors, and also a Catalogue according to subjects."

The Committee succeeded in interesting the Royal Society of London in the undertaking, and that body ultimately assumed the direction of the work.

But they have achieved an instalment only of the recommendation of the distinguished Committee at whose suggestion they took action. They have produced an author-list, but the "Catalogue according to subjects" is wanting. All the subjects in the Royal Society's Catalogue should be at once placed under a subject-heading as well as under the author-heading in alphabetical arrangement, as near a concordance as possible by means of crossreferences, and should be systematically continued and published annually. What has been done by Mr. Poole, of Chicago, for the great portion of English general periodical literature in publishing a subject-list, alphabetically arranged, of the articles contributed to 238 periodicals from $1802-8 \mathrm{I}$, and to $14 \mathrm{I}$ periodicals in the supplemental volume for $1882-87$, should be done for all the scientific publications. The principle of the work is simple, and could be readily carried out. "The main purpose of this (Poole's) work was to meet the average wants of students, literary men, and writers for the press--in other words, to help general scholars, who are many, in preference to the few who give their whole attention to a single topic." From an experience of thirty-two years in libraries, I must say, with all due deference to Mr. Poole, that a subject-index of the scientific journals would be of vastly greater benefit to the community--material benefit, if he pleases. I ought, however, to add my meed of praise to the practical, sensible, and sufficient way in which the work that he attempted has been done.

An attempt at remedying our great literary defect was made by Robert Watt, 1819-24, when he added to the two quarto volumes of an alphabetical list of 40,000 authors in his "Bibliotheca Britannica, or General Index to British and Foreign Literature," an additional two volumes of an index of subjects. 'This has all the disadvantages of a first attempt. The study of bibliography was little known, and less cultivated, at the time. The book is almost entirely out of date. A great deal more may be said in favour of the combination of authors and subjects in one general catalogue, as successfully achieved by Lieutenant-Colonel Billings in the "Index Catalogue of the Library of the Surgeon-General's Office, United States Army," as far as the letter N, in nine volumes, royal octavo. This is a specimen of cataloguing almost perfect : every article, and every disease, and the complications of every disease, with the various organs, being catalogued and sub-catalogued with their crossreferences.

The history of scientific research exhibits a continual tendency towards specialization; and as the sphere of the labourer has become limited each area of research has expanded, so that it has become essentially necessary that every subdivision of knowledge should be digested and arranged. With the co-operation of a few librarians, a subject-catalogue of all scientific literature might be readily undertaken by the Royal Society or the Society of Arts, the publications contained in the British Museum being marked by an asterisk or other sign. Or a system similar to that of the "Smithsonian Catalogue of Scientific and Technical Periodicals (1665-1882)" might be 